\title{
GLOBALIZACIÓN, CENTRO Y FRONTERAS SIMBÓLICAS EN LA TEORÍA SOBRE LA SOCIEDAD CONTEMPORÁNEA
}

\author{
ENRIQUE LARAÑA \\ Universidad Complutense de Madrid
}

\author{
PALABRAS CLAVE ADICIONALES \\ ADDITIONAL KEYWORDS \\ Modernización y cambio social, Postindustria- \\ lismo e informacionalismo, Construcción social, \\ Reflexividad social. \\ Modernization and Social Change, Information \\ Society and Postindustrialism, Social Construc- \\ tionism, Social Reflexivity Theory.
}

\begin{abstract}
RESUMEN. Este trabajo analiza algunas implicaciones del proceso de globalización de las sociedades occidentales desde una perspectiva constructivista y sostiene que la magnitud de los cambios generados por ese proceso requiere una revisión en profundidad de la teoría sobre la sociedad moderna. Para ello, se presta especial atención a la crisis de la imagen monolítica de la sociedad y de la teoría funcionalista sobre la unidad del saber en la Universidad. El trabajo examina la influencia que ha tenido la idea según la cual existe un lugar central institucional que genera los criterios para la evaluación de los conocimientos y regula las relaciones entre el orden tecnoeconómico, la política y la cultura en las sociedades de la información.
\end{abstract}

SUMMARY. This paper focuses on specific implications of the process of globalisation taking place in Western societies and the efforts to build a theory of modern societies by several classic and contemporary sociologists. It argues that the scope of the changes generated by this macro process requires an in depth revision of the theory of modern society. For that purpose, it also focuses on the breakdown of the monolithic image of the latter and the functionalist model of the unity of knowledge at the University, which are interrelated. It reviews the influence of the idea that there is symbolic centre of society which provides the basis for the evaluation of knowledge and which regulates the boundaries between the economy, politics and culture in information societies.

E-mail: elarana@cps.ucm.es

Revista Internacional de Sociología (RIS)

Tercera Época, n 28 , Enero-Abril, 2001, pp. 209-240. 
RIS

REIISTA INTERNACIONAL DE SOCIOLOGIA

$N^{n} 28$. Enero-dbril. 2001

ENRIQUE LARAÑA

\section{CENTRO SIMBÓLICO Y HEGEMONÍA CIENTÍFICA}

En su primera carta a los miembros de la Asociación Internacional de Sociología, su anterior presidente hizo un balance de la evolución de esta disciplina en el mundo y destacó los sentimientos de insatisfacción con esta Asociación, que atribuyó a su historia reciente y a los cambios que se han producido en el mundo desde que fue fundada. Wallerstein (1994) destacó la quiebra de la hegemonía científico-cultural de Estados Unidos como algo correspondiente a un tiempo en que esa nación ostentaba la supremacía en la economía mundial, dominaba la escena sociopolítica y constituía "el lugar principal de la producción intelectual" en el mundo. El interés de este argumento, que el autor había desarrollado en un trabajo anterior (1992), radica en la relación que establece entre los factores de las políticas científicas. Esa situación habría cambiado desde que el monopolio científico-cultural de EE.UU. empezó a perder fuerza a raíz del resurgimiento económico e intelectual de Europa Occidental y el proceso de autoafirmación política del Tercer Mundo. Otros factores que habrían contribuido a ese cambio eran la caída del muro de Berlín y la recuperación de la legitimidad de la sociología en Europa del Este desde entonces, así como el desarrollo económico de Asia Oriental y Japón, que se consideraba paralelo al aumento de su contribución a la producción científico-social. Una concepción similar de las relaciones sociales que subyacen a las posiciones científicas informaba el libro oficial del Congreso Mundial de Sociología de Bielefeld (1994), Sociology in Europe. In Search for Identity. Uno de sus temas centrales consistía en dilucidar si la producción sociológica en Europa presentaba características distintivas y había superado su posición subordinada respecto a la norteamericana. El pronóstico de los editores es que las próximas décadas iban a presenciar "otra Edad de Oro de la Sociología europea, que sólo podría compararse con la gran cosecha del siglo pasado" (Nedelman y Stompka, 1994).

Estos argumentos plantean una cuestión central en el estudio de los procesos de globalización en las sociedades occidentales: la existencia de un lugar institucional que desempeña un papel central en la producción de la clase de conocimiento al que algunos analistas atribuyen la capacidad de organizar y transformar a aquellas (Bell, 1976, 1977, 1980; Masuda, 1984; Naisbit, 1983; Castells, 1997). Ese lugar constituiría el centro simbólico de la sociedad contemporánea, una de cuyas funciones consiste en establecer límites entre las instituciones básicas de ese tipo de sociedad, entre los departamentos y centros de investigación donde se producen esos conocimientos y entre lo que se considera ciencia y lo que no. Esta imagen de la sociedad, fundada en la existencia de un centro simbólico, informa influyentes aproximaciones a la modernización de las sociedades occidentales, algunas de las cuales han popularizado términos como "sociedad postindustrial" o "de la información" para designar ese proceso de cambio. 
El objetivo de este trabajo consiste en examinar algunas implicaciones teóricas y epistemológicas de esos trabajos y profundizar en la relación que existe entre los cambios en la sociedad y en las categorías empleadas para explicarlos. Para ello, voy a basarme en dos supuestos interrelacionados con los que he trabajado en los últimos años. El primero se centra en los aspectos cognitivos y epistemológicos de los procesos de modernización, en su influencia en los marcos de significados con los que las personas interpretan la realidad y en las formas de acercarse a ella por parte de los científicos sociales. La segunda idea se refiere a la naturaleza de las categorías sociológicas en las que se fundan las aproximaciones científicas, y destaca su carácter históricamente construido, ya que son herramientas elaboradas para dar cuenta de los acontecimientos que se están produciendo en la sociedad y de su conexión con los hechos depende su sentido (Melucci, 1996; Laraña, 1999). Mi argumento es que las transformaciones sociales que suelen designarse con el término "globalización" se refieren a procesos que están teniendo un impacto epistemológico y social en algunas categorías sociológicas muy empleadas, entre las cuales destacan las que se aplicaban para explicar las relaciones entre la estructura social y la acción colectiva, y entre el orden tecnoeconómico y la cultura. Los conceptos 'estructura social', 'clase social' y 'movimiento social', que han ocupado un papel central en la literatura sociológica debido a la capacidad explicativa que se les atribuía, se encuentran entre los primeros en acusar ese impacto. El desarrollo de los enfoques constructivistas en la última década es consecuencia del intento de abordar estos cambios desde una perspectiva diferente y reconstruir algunas de las herramientas con las que se había erigido el edificio de la sociología de la modernización. Desde supuestos más ambiciosos y diferentes, las teorías de la modernización reflexiva responden a ese mismo esfuerzo.

Este trabajo se inscribe en una perspectiva constructivista que he desarrollado en anteriores trabajos y presta especial atención a algunos problemas conceptuales con los que se enfrentan las ciencias sociales al final del siglo (Laraña, 1999, 2001a y b). Desde esa perspectiva, Alberto Melucci (1996) señaló que la inadecuación de muchos conceptos sociológicos para interpretar los procesos contemporáneos de cambio social genera una situación de desfase lingüístico y cultural, en la que los científicos sociales nos encontramos atrapados. Los debates sobre la modernidad y la postmodernidad que se vienen produciendo en los últimos años representan un intento de salir de dicha situación' ${ }^{1}$. Para el

\footnotetext{
'Melucci describe esta situación con una conocida metáfora: el problema es que nos ha dejado 'oscilando como un péndulo entre una terminología obsoleta, que todavía empleamos porque no tenemos otros instrumentos cognitivos, y una serie de conceptos... que sólo contienen referencias alusivas a los hechos, desprovistas de significado analítico" (Melucci, 1996: 89)
} 
RIS

RETISTA INTERNACIONAL DE SOCIOLOGI.

N" 28. Enero-.tbril. 2001

ENRIOUE LARANA

sociólogo italiano, el primer paso para ello consiste en reconocer la dimensión del problema y la debilidad de nuestras herramientas analíticas para explicar lo que acontece en nuestras sociedades. Un ejemplo de este problema viene dado por la concepción de la sociedad contemporánea como una entidad estructurada por un centro simbólico. Esa imagen fue sustentada desde una perspectiva clásica diferente a la de Wallerstein en relación con un tema que ha cobrado actualidad en España a raíz del debate que ha suscitado la difusión del Informe Universidad 2000 (Informe Bricall) en los primeros meses de ese año. Me refiero a la teoría funcionalista que explicaba la hegemonía científico-cultural de los EE.UU. como resultado de la organización de su sistema universitario y de investigación sobre la base del principio de racionalidad cognitiva. Para Parsons y Platt (1975), la Universidad norteamericana es la institución que ha hecho posible la aplicación de ese principio, ya que en ella se realiza y evalúa la producción intelectual y cultural de EE.UU, y esa situación es la que ha producido la hegemonía científico-cultural de este país. Ello significa que la Universidad norteamericana ha dirigido la modernización del país al establecer los criterios para evaluar su creatividad en ese terreno, del cual depende la calidad de las instituciones educativas, y de ahí la importancia decisiva que desempeña esta institución.

De acuerdo con esa perspectiva, lo que hoy llamamos "sociedad moderna" es consecuencia de tres grandes revoluciones: la industrial, la democrática y la educativa, y el modelo de universidad norteamericana representa la culminación de la última. El sistema mixto de educación e investigación en que se articula ese sistema científico-cultural ha convertido a esa institución en el elemento rector del amplio proceso de cambio que se está produciendo en los demás subsistemas sociales. Profesionalismo es el concepto que designa la adhesión a un código de valores basado en la prioridad de aquéllos de carácter universal frente a los intereses particulares de cada uno. En la universidad estadounidense, el primer valor universal es el principio de racionalidad cognitiva y en él se articula la estructura normativa que regula los comportamientos para permitir su desarrollo. Este uso del término 'profesionalismo' se funda en la teoría funcionalista de la estratificación, que lo define como el conjunto de elementos culturales necesarios para desempeñar un puesto de trabajo a través de la cualificación y no del estatus - ya que el segundo se considera fruto del primero (Parsons y Platt, 1975; Davis, 1972). Por ello, el logro individual, en lugar de formas de adscripción vinculadas a intereses ajenos a los académicos, sería la base del profesionalismo en la Universidad, el cual constituye el criterio de acceso a las posiciones del sistema universitario norteamericano. De la adhesión a ese código de valores depende la vigencia del principio estructurante del sistema universitario (Parsons y Platt, 1975).

$\mathrm{El}$ argumento anterior se centra en los aspectos organizativos de unos procesos conceptualizados de forma más general en otros trabajos sobre la transformación de la sociedad occidental. De este modo, la hegemonía científico-cultural de 
los Estados Unidos sería el resultado de aplicar un modelo institucional que permite en la Universidad el más alto grado de ajuste a sus objetivos productivos y hace de ella la "institución axial" de la sociedad postindustrial, en la que se desarrollan los procesos de innovación y organización social de los que depende el crecimiento económico y la posición que cada país ocupa en la competencia internacional (Bell, 1976 y 1980). Estos supuestos también serían aplicables a otros países y en particular a la producción científica y cultural española, pero en un sentido opuesto al antes citado: para explicar lo que ha sido considerado como su "carácter periférico" y su atraso e inferioridad de condiciones frente a otros países occidentales situados más cerca de ese "centro científico-cultural" (Pérez Díaz, 1987). Esto último está en el origen de la controversia sobre las medidas destinadas a una reforma de la universidad española que promueve el Informe Bricall. Años antes, Pérez Díaz atribuyó la situación en que se encuentran dicha institución, y la producción científica y cultural en España,"al lugar secundario que ha ocupado la Universidad en nuestra sociedad, a diferencia de lo que sucede en EE.UU.

El argumento de Parsons y Platt contrasta con algunos supuestos desde los que se vienen estudiando los procesos de modernización y globalización de las sociedades occidentales en los últimos años. Me refiero al énfasis de los primeros en los fundamentos del principio de racionalidad cognitiva, que sitúan en el consenso vigente en el mundo académico en torno a un valor o principio que constituye el centro neurálgico del sistema universitario. Uno de los problemas de ese análisis es su preocupación por el mantenimiento de la unidad y el consenso en la institución, y por el riesgo de fragmentación del mismo como consecuencia de la proliferación de diferentes orientaciones teóricas. Lo segundo responde a la idea de que ese desarrollo genera "zonas grises", donde las proposiciones empleadas por unos son contestadas por otros, lo cual rompe el consenso académico y produce la fragmentación del sistema por escuelas de pensamiento que constituyen facciones rivales (Parsons y Platt, 1975: 109). A esta concepción del 'mundo académico', como un sistema social estructurado en torno al principio de racionalidad cognitiva, subyace una visión de la sociedad cuya congruencia resulta más difícil de sostener en la actualidad por las razones que expongo a continuación.

En el ámbito de la sociología, la interpretación funcionalista citada convierte al sistema universitario en el principal medio para ordenar los conocimientos y en un freno contra la tendencia de la sociología moderna hacia el pluralismo de escuelas y orientaciones teóricas que siguen supuestos a veces contradictorios entre sí. Y en general, la Universidad se considera que constituye el centro regulador del sistema científico y cultural, donde se diseñan las fronteras simbólicas entre distintas disciplinas, las cuales mantienen la unidad del sistema educativo y previenen la disgregación del saber. La posibilidad de evaluar la producción de conocimientos se funda en la existencia de ese lugar central, 
RIS

RETISTA INTERNACIONAL DE SOCIOLOGI.A

$N^{*}$ 28. Enero-Abril. 2001

ENRIOUE LARAÑA

del que provienen las normas y procedimientos para ello y en el cual radica el principio de autoridad científica en el que se articula el sistema.

\section{LA CONSTRUCCIÓN DEL ORDEN ACADÉMICO}

En mayor o menor grado según el desarrollo científico de cada país, es innegable que esas funciones son desempeñadas por el sistema universitario. Pero mi argumento es que ese desarrollo se funda en procesos de interacción social mucho más fluidos y complejos, en lugar de en la existencia de un consenso basado en criterios compartidos para la valoración de los conocimientos científicos. El consenso en ese terreno suele ser resultado de procesos de interacción, negociación y conflicto, y se construye sobre acuerdos mucho menos estructurados y menos basados en la conformidad con unas estructuras normativas previamente establecidas, ya que se articulan en torno a los principios que constituyen el centro del sistema. El consenso sobre esas estructuras se refiere a cuestiones de forma y procedimiento, pero no se basa en unos contenidos y criterios científicos aplicables en todos los casos. En lugar de ello, la evaluación de los conocimientos se atiene a procesos de construcción social en los que se gestan acuerdos pragmáticos o 'consensos de trabajo' (working consensus), que no se diferencian sustancialmente de aquéllos en los que se funda el orden de la interacción en la mayoría de las instituciones sociales.

El concepto 'consenso de trabajo', que tiene una importancia central en análisis de la sociedad y las formas de consenso que surgen en los grupos y movimientos sociales, proviene de la sociología interaccionista y fue empleado por Goffman (1959) para designar la naturaleza cambiante y fluida de las estructuras sociales y la forma en que influyen en los comportamientos, así como los aspectos expresivos de la interacción en sociedad y su carácter de representación simbólica. El concepto enlaza con un supuesto central de la sociología cognitiva sobre la necesidad de contextualizar los conceptos sociológicos en el marco natural de la vida cotidiana con el fin de integrar los aspectos macro y micro sociológicos de la realidad —el cual ha sido formulado en términos de la producción local de las estructuras sociales (Cicourel, 1981, 1982). Si queremos conocer cómo influyen en la acción social lo que los sociólogos solemos llamar estructuras sociales, y a las que conferimos especial capacidad para explicar la primera, es preciso recrear y contextualizar esas herramientas analíticas en la vida diaria, conocer su significado para las personas en ese ámbito microsociológico de la acción social. No podemos entender la forma en que esas estructuras influyen en el comportamiento social sin saber cómo piensan y sienten los individuos en su vida diaria, lo cual requiere conocer las "ideas vulgares" con las que las personas interpretan su medio y se orientan en sus relaciones con los demás. Esas ideas son estructuras de sentido que 
se construyen en la interacción y guían el comportamiento de las personas, modificando y/o atribuyendo significado a las estructuras sociales.

Estos supuestos sobre la interacción social son aplicables a la que tiene lugar en la Universidad y constituye el marco de relaciones sociales en el que se aplica el citado principio de racionalidad cognitiva. No hay ninguna razón para atribuir a la estructura normativa vinculada a ese principio mayor eficacia que a otras estructuras sociales. El sistema universitario no es más que uno de los contextos institucionales donde son aplicables estos supuestos sobre el orden de la interacción, los cuales no tienen por qué diferenciarse de los que siguen las personas para relacionarse en la vida cotidiana. Esto significa que el principio de la racionalidad de los conocimientos es un objeto de negociación que se construye a través de la interacción, la negociación y el conflicto en la Universidad, en lugar de ser fruto de una estructura normativa previa, conocida y compartida por la mayoría de los que se relacionan con ella.

Goffman (1959) se basó en su inicial investigación en las islas Shetland para analizar las razones pragmáticas en las que se fundan los acuerdos a los que llegan las personas en la interacción cara a cara. En lugar de considerarlos resultado del carácter coactivo de unas normas institucionales, atribuyó esos acuerdos a la tendencia a aceptar las definiciones de la situación que promueve un grupo para mantenerlo funcionando. Esas formas de acuerdo no se basan en la homogeneidad de los valores y definiciones de las situaciones con que se enfrenta el grupo, sino en razones de adaptación mutua destinadas a permitir la interacción y subsistencia del grupo. El concepto consenso de trabajo responde a dos reglas de la interacción social: el respeto por uno mismó y la consideración por los otros con los que interactúa. Ello significa que cada uno no sólo tiene que mantener su propia imagen, sino también la de esas personas, lo cual permite a todos desempeñar sus roles sociales. Desde esa perspectiva interaccionista, he expuesto la utilidad de este concepto para analizar las formas de unión entre las personas que participan en movimientos sociales (Laraña, 1999)2 ${ }^{2}$.

\footnotetext{
${ }^{2}$ Goffman (1959) destacó el efecto conservador de estas formas de consenso, ya que protegen aquellos roles que no se modifican y ya han sido aceptados, mientras que las modificaciones que se introducen en ellos pueden producir confusión en un grupo social. Mantener la imagen de cada uno es simplemente una condición para la interacción en un grupo social, no su objetivo. Y estudiar las prácticas que están orientadas de esa manera implica analizar las reglas de la interacción que sigue cada individuo, las cuales pueden radicar en su implicación emocional con la imagen que pretende proyectar en el grupo, o con la de los otros miembros del mismo. El "trabajo de imagen" (face-work) es el concepto que alude al trabajo de una persona destinado a hacer que sus acciones sean consistentes con su imagen social; cada subcultura, cada persona y cada sociedad parecen tener sus propias normas en este terreno.
} 
RIS

REIISTA INTERNACIONAL DE SOCIOLOGIA

N" 20. Enero-tbril. 2001

ENRIQUE LARAÑ

Estos supuestos sobre el orden de la interacción en las instituciones sociales son congruentes con una conocida aproximación a la historia de la tecnología (Mokyr, 1993) y con mi observación de lo que ocurre en situaciones de evaluación de los conocimientos en las universidades españolas y norteamericanas. Una posible objeción consiste en que dicha información no es extrapolable a lo que sucede en otras más avanzadas y más firmemente organizadas sobre la base del principio de racionalidad cognitiva. Sin embargo, los supuestos citados no sólo son aplicables a los procesos de evaluación de los conocimientos que se tienen lugar en Estados Unidos, sino que desempeñan un papel básico en su sistema universitario, que sigue considerado como el más avanzado del mundo. Este análisis se funda en la pluralidad de orientaciones teóricas muy diferentes que han adquirido legitimidad académica en Estados Unidos durante la segunda mitad del siglo, desde la sociología cognitiva a la histórica, pasando por el interaccionismo simbólico y la teoría de la elección racional. El desarrollo del sistema que mejor combina docencia e investigación contrasta con la interpretación de Parsons y Platt, la cual sitúa las bases de la racionalidad de los conocimientos en la unidad del sistema frente a las amenazas de fragmentación generadas por el pluralismo científico. Por el contrario, ese desarrollo representa la manifestación académica de un proceso más amplio de cambio social, que puede designarse en términos de multiculturalismo cientifico. Uno de los factores que han impulsado ese desarrollo es la fluidez de las relaciones existentes entre la universidad y la sociedad en EE.UU., lo cual potencia que la interacción entre investigadores, que también ejercen la docencia, se articule en los mismos supuestos en los que se basa la interacción social. En ese vínculo se funda la racionalidad de ese sistema universitario, ya que confiere sentido y mecanismos de control al profesionalismo de sus miembros y a su teórica sumisión al principio de racionalidad cognitiva.

Las bases microsociológicas del análisis anterior se complementan con otras de carácter macro que provienen de la investigación de los procesos de desarrollo tecnológico. Mokyr (1993) ha identificado el impulso de creatividad tecnológica en un acto de rebelión contra el estado de cosas existente - cuya justificación se daba por hecho- con el fin de mejorar las condiciones de vida de las personas. La creatividad tecnológica ha caracterizado a las sociedades occidentales, en las que se ha fundado su superioridad y su crecimiento económico, ya que ha producido un incremento de la producción que es desproporcionado al incremento en el esfuerzo y en el coste necesario para conseguirlo (op. cit.: 18). Esa interpretación es congruente con su definición de la tecnología como "capacidad para controlar y manipular la naturaleza y las personas con fines productivos" (op. cit.:11), y contrasta con la teoría funcionalista, debido a la importancia que la segunda confiere a un grado de conformidad con las normas que no parece compatible con el citado impulso de rebelión ante situaciones dadas en que este historiador sitúa la palanca de la riqueza. 
Las tendencias hacia el pluralismo epistemológico y la interdisciplinariedad que han impulsado el desarrollo de las ciencias sociales en las últimas décadas cuestionan también la concepción de la sociología como una disciplina unificada. Este último supuesto informa la citada valoración de una sociología europea que estaría haciendo frente a la hegemonía de la norteamericana (Needelman y Stompka, 1994). Sin entrar en la veracidad de tan optimista afirmación (a la que me refiero a continuación), el desarrollo de esta disciplina contrasta con ella en la medida en que da por hecho la existencia de un telos o principio unificador de la sociología europea. La vigencia de tal principio tendría que ser resultado de un consenso previo sobre los criterios aplicables, lo cual es bastante dificil que se produzca debido a la diversidad de supuestos de interpretación y orientaciones teóricas y metodológicas en la sociología contemporánea en estos dos continentes. En un área cada día más importante como es la que estudia los movimientos sociales, esos rasgos representan un obstáculo para el desarrollo"de su marco conceptual y la acotación de un concepto tan amplio como éste (Diani, 1992; Melucci, 1996; Laraña, 1999). Mi argumento consiste en señalar que ese pluralismo tiene efectos positivos para ello, ya que genera un debate interno que potencia la reflexividad de la sociología contemporánea, al desarrollar las herramientas analíticas y estimular intentos de síntesis entre distintas aproximaciones a los movimientos sociales.

$\mathrm{Al}$ igual que sucede con el debate sobre las consecuencias de la modernización y los riesgos que genera (Beck, 1992), el que aquí nos ocupa nunca puede producirse al margen de las estructuras de poder y los intereses en juego de las distintas redes profesionales. Como hace tiempo planteó Weber (1969), carece de sentido plantear un debate científico al margen de esos elementos, debido a la influencia que tienen en los contextos de la interacción en la Universidad $\mathrm{y}$ en los discursos en los que se fundan las decisiones sobre políticas públicas relacionadas con estos riesgos. Mi argumentación anterior, sobre la necesidad de contextualizar el significado de las estructuras sociales en la vida cotidiana no sólo no choca con este supuesto sino que lo desarrolla, al orientar nuestra atención a ese plano microsociológico, donde se manifiesta el peso de las reglas que guían interacción y su capacidad para modificar la eficacia normativa de las primeras.

\section{LA CULTURA COSMOPOLITA}

Mi argumento consiste en afirmar que, si las universidades norteamericanas tienen el más alto nivel de producción y prestigio en la sociología contemporánea, y las publicaciones en libros y revistas editadas en Estados Unidos son las más importantes en términos del prestigio que confieren, al igual que sucede con el hecho de haber estudiado en las buenas universidades norteamericanas, parece 
RIS

RETISTA INTERNACIONAL DE SOCIOLOGIS

N" 28. Enero-Abril. 2001

ENRIQUE LARANA

necesario buscar las razones de esa situación en un desarrollo muy diferente al que plantea la teoría antes citada. En lugar de un sistema unificado por un principio central que ha velado por la ortodoxia académica, el desarrollo de las instituciones universitarias más importantes se ha distinguido por el pluralismo científico y la capacidad para combinar una cultura científica cosmopolita con criterios de especialización del trabajo científico. En esa síntesis radica gran parte del vigor del sistema universitario. Por una parte, rige el principio de división del trabajo, que desde Smith y Durkheim es considerado por una amplia tradición científico-social como el motor del cambio social; por otra, la globalización de los procesos de producción, que se manifiesta con especial intensidad en el campo de la investigación científica y en la intensificación de los intercambios profesionales. El segundo proceso complementa y confiere racionalidad al primer principio, ya que el desarrollo de la innovación científica está íntimamente relacionado con el aumento de la densidad de interacción entre los que trabajan para conseguir dicha meta.

La interacción social se convierte en una condición básica para el desarrollo de la ciencia en las sociedades contemporáneas, como ha sucedido en los contextos en que se han producido innovaciones fundamentales en las nuevas tecnologías de la información (Castells, 1997). Algunos logros en este campo, y en especial la difusión de Internet, han potenciado decisivamente ese proceso de incremento de la densidad de interacción dentro y fuera de las instituciones de investigación, si bien esa tendencia se dispara y anticipa en las primeras. El desarrollo de estas tecnologías ha confirmado el pronóstico de Durkheim (1985) al identificar el aumento de la densidad de interacción como un aspecto central de la sociedad moderna. Esa red de redes, que ha producido un nuevo 'mercado de la información', tiene una característica constitutiva en la ausencia de un centro neurálgico en el sistema de comunicaciones, puesto que la creación de tal sistema acéfalo fue el objetivo inicial de las investigaciones promovidas por el Pentágono, que tuvieron como resultado Internet (Castells, 1997).

Dos décadas antes de su masiva difusión, Bell señaló los dos tipos de interacción que potencian la imagen de un mundo interconectado visionada por McLuhan. "Lo distintivo de nuestra sociedad contemporánea no es su tamaño ni su número, sino el incremento de la interacción - tanto física (mediante los viajes, las unidades de trabajo más vastas, una mayor densidad de viviendas), como psíquica (a través de los medios masivos de comunicación) - que nos vincula con tantas otras personas, directa y simbólicamente" (1977: 94). Ambas formas de interacción, social y parasocial, han adquirido central importancia en la producción de conocimientos y se convierten en una condición para ello. Bell (1976) ha explicado este proceso en relación con el cambio en la naturaleza de los problemas con que se enfrenta la ciencia hoy y el surgimiento de una nueva 'tecnología intelectual'. El aumento en la complejidad de los problemas que debe resolver es consecuencia del que se produce en el número de variables con 
que se enfrentan los políticos y científicos, lo cual hace necesario que elaboren estrategias cada vez más sofisticadas, y más teóricamente fundamentadas, para integrarlas y resolver esos problemas. Dada la naturaleza de las ciencias sociales y el pluralismo de orientaciones teóricas dentro de cada disciplina, esa tarea precisa del intercambio con otros profesionales, para introducir puntos de vista que permitan integrar y comprender una amplia serie de hechos y procesos sociales. Esa tendencia no sólo se manifiesta dentro de este campo, sino en la aplicación de principios interdisciplinares en la estructura de trabajo en equipo.

De ahí la importancia que adquieren los elementos cosmopolitas de la subcultura científica contemporánea, la multiplicación de encuentros científicos y estructuras de trabajo que siguen principios de análisis comparado y normas ad-hoc de interacción social. Ese proceso de carácter general se manifiesta de muchas formas, que podemos concretar en actitudes de apertura a la innovación, caracterizadas por un creciente de interés por los supuestos de interpretación procedentes de otras culturas y por formas de racionalidad diferentes ${ }^{3}$. Esa subcultura científica tiene raíces históricas en un país como Estados Unidos, que se construyó con fuerza de trabajo procedente de la emigración en todos los ámbitos, incluido el científico-cultural, lo cual ilustra la congruencia entre esa subcultura y la arraigada tradición de acogida de emigrantes en ese país.

Los cambios que están teniendo lugar en los procesos de producción de conocimiento no parece que puedan interpretarse adecuadamente desde los supuestos funcionalistas antes citados, debido a su énfasis en la necesidad de evitar fraccionamientos y preservar el 'orden cognitivo' de la Universidad desde unos supuestos muy rígidos. En el ámbito de la sociología contemporánea, una razón básica radica en que dicha concepción del orden no es congruente con la realidad porque no existe el principio central de racionalidad cognitiva en que se fundaría el primero. El desarrollo de los conocimientos científicos se caracteriza por procesos de mayor complejidad que son difícilmente compatibles con tal principio, ya que el pluralismo de orientaciones teóricas no ha producido la fragmentación del saber, sino formas de interacción y multiculturalismo científico que impulsan ese avance. Para profundizar en ello, la literatura sobre modernización social brinda algunas ideas útiles y presenta algunos problemas, que por razones de espacio sólo pueden esbozarse a continuación.

\footnotetext{
${ }^{3}$ En la sociología contemporánea, estos rasgos se manifiestan también en la importancia que han adquirido las nuevas orientaciones citadas, las cuales confieren especial importancia al estudio del sentido común y profundizan en los métodos y marcos de significados a partir de los cuales los individuos confieren sentido al mundo que les rodea (Cicourel, 1971 y 1982; Goffman, 1959 y 1974).
} 


\section{IDEOLOGÍA MODERNISTA Y TEORÍA SOBRE LA MODERNIDAD}

Hace más de veinte años, Daniel Bell (1977) hizo una crítica a las concepciones tradicionales de la sociedad y su proceso de modernización que está relacionada con la exposición anterior y ha tenido una influencia considerable (Lyon, 1988). Bell cuestionó la validez de las aproximaciones estructuralistas clásicas (funcionalismo y marxismo) porque se fundamentan en una concepción de la historia y la sociedad según la cual ésta constituye una totalidad estructuralmente entrelazada, unificada por un principio interno, el telos que confiere sentido al devenir histórico de la sociedad e integra sus distintos elementos. Ese principio unificador radicaba en el devenir del espíritu objetivo para Hegel, en el modo de producción, para Marx, en el triunfo del pensamiento positivo, para Comte y, en la extensión de los sistemas de acción racional a todos los ámbitos de la existencia, para Weber ${ }^{4}$. Estos enfoques respondían a una imagen monolítica de la sociedad, en la que ésta se concebía como una roca constituida por un solo bloque y unificada por un principio central interno en el que se situaban las causas de los hechos sociales. La sociedad se consideraba resultado de tal principio unificador, que operaba en un ámbito de la sociedad (la estructura social o el orden tecnoeconómico) y determinaba lo que sucedía en los demás.

La concepción monolítica de la sociedad tiene sus pilares en el pensamiento moderno y se manifiesta en los sociólogos clásicos y en los filósofos de la Ilustración, como puede verse en la obra de Hegel, uno de los que más han influido en ese pensamiento. Uno de sus teoremas centrales - "lo racional es real y lo real es racional" - sintetiza su concepción de las relaciones entre ambas cosas y su romántica fe en el desarrollo de la Razón Occidental. Ello implica que lo real no es la realidad, que se presenta ante nosotros fragmentada y vacía de sentido, sino la estructura conceptual del sujeto que confiere sentido a la primera al situarla en un orden lógico, en un sistema estructurado por el devenir de la Razón 5 . Para Bell, dicha concepción de la relación existente entre la realidad y la razón humana es paralela a la que existe entre la sociedad y la naturaleza en tanto que sistemas históricamente enfrentados, y se funda en una visión de la

\footnotetext{
${ }^{4}$ Dicha concepción sólo influyó en una de las dos visiones de Weber sobre la modernización de la sociedad industrial como un desarrollo lineal sin retrocesos. Pero su teoría de la burocracia como una jaula de hierro de la que nadie escapa sigue una lógica de interpretación diferente, que se caracteriza por su ambivalencia y por una mayor complejidad.

s En su condición de filósofo del Gran Rechazo de la sociedad capitalista e ideólogo de los movimientos de la Nueva Izquierda, Marcuse llevó al extremo esa idea al afirmar que 'si los hechos se enfrentan a la Razón, tanto peor para los hechos'.
} 
historia como progresiva conquista de la primera sobre la segunda, merced a la expansión de la razón "en cuanto actividad reflexiva autoconsciente de la inteligencia" (1976: 391). La ciencia, en tanto que producto de la razón humana, constituye el principio germinativo del cambio social. Esa dialéctica informa las teorías sociológicas sobre la sociedad industrial de Occidente, y una razón para ello es el carácter históricamente construido de las ideas con las que se interpreta la realidad, tanto en las ciencias sociales como en la vida cotidiana de las personas (Melucci, 1996). Esa concepción de la razón y de las relaciones entre cultura y naturaleza concordaba con la experiencia de los hombres en el siglo XIX, que presenciaban un proceso de transformación social tan profundo como el que está teniendo lugar al final del siglo XX en Occidente. En ello se fundaba la visión prevaleciente de la Historia como progreso continuo. Para Touraine (1993), esa visión es consustancial a la cultura moderna, ya que constituye una ideología basada en la tensión entre lo moderno y lo antigúo, con arreglo a una concepción historicista del cambio social según la cual el crecimiento económico, la libertad política y la felicidad personal avanzan al mismo tiempo en las sociedades industriales, y "todo problema social es en última instancia una lucha entre el pasado y el futuro".

"El sentido de la historia es a un tiempo su dirección y significación, porque la historia tiende al triunfo de la modernidad, que es complejidad, eficacia, diferenciación y por tanto racionalización, al mismo tiempo que ascenso de una conciencia que es en sí misma razón y voluntad sustituyendo a la sumisión al orden establecido y las herencias recibidas" (Touraine, 1993: 89).

Touraine señala que esa concepción del progreso está dominada por la idea de totalidad que identifica el desarrollo del espíritu con el triunfo de la razón y de la libertad, y el crecimiento económico con el desarrollo de la nación (1993). Es una concepción organicista del cambio social, ya que se basa en una concepción biológica del crecimiento y en la metáfora de la semilla, la cual constituye el centro germinativo de la planta y se convierte en el símbolo del cambio social. Desde la Antigüedad nuestra civilización ha estado poderosamente influenciada por unas concepciones del progreso cuyo común denominador consistía en identificarlo con un tipo de crecimiento análogo al que se produce en el organismo humano (Nisbet, 1979). Se trata de una "metáfora", una de las más antiguas formas del conocimiento humano, por la cual las propiedades de un objeto son sintetizadas y, de forma instantánea, casi inconsciente, transferidas a otro desconocido para nosotros. "En la civilización occidental, la noción de cambio en la cultura o en la estructura social connota unos atributos determinados: dirección, acumulación, irreversibilidad y propósito" (Laraña, 1984: 251). En esa concepción organicista se han fundado las aproximaciones al cambio en las sociedades humanas, cuyas fases de crecimiento se interpretan por 
R IS

RETISTA INTERNACIONAL DE SOCIOLOCIA

N*28. Enero-Abril. 2001

ENRIQUE LARAÑ

analogía con lo que sucede en las plantas o en el organismo de los seres vivos.

Esa concepción cíclica del cambio informa otra, historicista y lineal, que la sustituye y prevalece en las sociedades occidentales desde la Revolución Industrial. Sus semillas fueron sembradas por la primera, la cual concebía a los ciclos de crecimiento como secuencias de cambio más o menos desvinculadas de su dimensión temporal, como fases de desarrollo y no como periodos históricos ${ }^{6}$ (Nisbet, 1979). A pesar de la importancia que confiere a la historia, la imagen prevaleciente de la modernización que se difunde desde el siglo XVIII tampoco se centra en el análisis de esos periodos, sino que los concibe como fases en el desarrollo de la racionalidad occidental. Esa creencia en la continuidad de un proceso irreversible de transformación social se funda en otra previa sobre el papel de la ciencia para resolver los problemas sociales. Ambos supuestos informan las teorías de los sociólogos clásicos sobre la sociedad industrial y se basan en la analogía que desde esta perspectiva se establece entre cambio social y crecimiento orgánico. El primero se considera resultado de una serie de modificaciones lentas y graduales, cuyas raíces se encuentran en el interior del objeto en transformación. "Por consiguiente, el pasado no es más que el principio de este continuo, el punto de partida de una serie de secuencias de cambio, en las que hay que centrar nuestra atención para explicar la génesis de las transformaciones que se producen en la vida del hombre" (Nisbet en Laraña, 1984: 253).

Una aproximación diferente al cambio social se centra en el papel de la historia y en los hechos externos a la estructura en transformación, los cuales desempeñan un papel central en su transformación a pesar de no formar parte de ella (Balandier, 1971; Gerth y Mills, 1964). A diferencia de la concepción historicista del progreso, esta aproximación no concibe la historia como un desarrollo lineal hacia metas más altas de bienestar, justicia y felicidad, que serían consecuencia de la expansión de la ciencia moderna, sino como un proceso complejo, en el que los avances en ese terreno alternan con retrocesos y en el que cada periodo histórico presenta características propias, que es preciso analizar porque no vienen determinadas por una trayectoria irreversible de progreso. En este sentido se orientan las aproximaciones constructivistas y las que enfatizan las consecuencias no queridas de la modernización. En el marco de las primeras, he aplicado estos supuestos al estudio de los movimientos sociales en España en un libro reciente ${ }^{7}$. El interés de los movimientos sociales para el tema que aquí

\footnotetext{
'Una aproximación diferente al cambio social se centra en el papel de la historia y en los hechos externos a la estructura en transformación, que desempeñan un papel central en su transformación a persar de no formar parte de ella (Balandier 1971; Gerth y Mills 1964).

${ }^{7}$ Para ello, he ampliado la tipología histórica propuesta por Álvarez Junco (1994) con el análisis de los marcos de acción colectiva y de las relaciones entre movimientos y partidos políticos.
} 
nos ocupa radica en que han sido considerados en la literatura sociológica como las principales agencias de modernización, como personajes que conducen a la sociedad hacia un destino de progreso y emancipación colectiva (Melucci, 1996). La creencia en la continuidad de los movimientos en el tiempo estaba relacionada con la visión historicista del cambio social que acabo de exponer. Ambas cosas son cuestionadas por los acontecimientos que se están produciendo en las sociedades complejas desde hace años, y en ello se ha fundado nuestra propuesta de abandonar la imagen moderna de los movimientos (Melucci, 1996; Laraña, 1999).

En relación con esto, Touraine ha destacado que esa concepción historicista de la modernidad prescinde de los actores sociales en la explicación de ésta, afirma ante todo la "muerte del Sujeto" y tiene en el materialismo su principal corriente filosófica (1993). Estas características son congruentes con la concepción moderna del cambio social, cuyas causas se sitúan en el interior de la sociedad, en su potencial de racionalización, desarrollo científico y progreso, el cual conduce a sus miembros a mejorar continuamente sus condiciones de existencia (Comte, 1980; Moya, 1970). Ese desarrollo se considera el principio germinativo de la modernidad y, por ello, Touraine (1993) señala que la "idea de modernidad" se encuentra estrechamente asociada a la de "racionalización" y renunciar a una es rechazar la otra. En el período en que esa identidad era más fuerte, esa concepción, que domina al pensamiento occidental, intentó "pasar del papel esencial reconocido a la racionalización, a la idea más amplia de 'sociedad racional', en la que la razón no sólo ordena la actividad científica y técnica, sino el gobierno de los hombres tanto como la administración de las cosas" (op. cit.: 24). Es la teoría del cambio social promovida por aquellos visionarios pioneros de la Sociología que fueron Comte y Saint-Simon. La aplicación del conocimiento científico a todos los asuntos sociales y económicos explica la dirección histórica de progreso, material y cultural, en la que radica la 'ley de la sociedad industrial' y su primacía sobre todas las demás (Aron, 1971). Esa visión informa la teoría sobre la universidad americana de Parsons y Platt (1975), en la que la ciencia suministra la unidad de criterios en los que se funda el sistema de evaluación de los conocimientos y su aplicación a los asuntos sociales en forma de tecnología.

\section{LA QUIEBRA DE LA CONCEPCIÓN MONOLÍTICA DE LA SOCIEDAD}

Parte del interés de la obra de Touraine en este tema proviene del argumento anterior, que se basa en su extenso estudio de los movimientos sociales. Ello le permite contrastar la teoría con la realidad y abordar la crítica de la modernidad como una ideología que ha prevalecido en Occidente durante los dos últimos siglos. Uno de sus rasgos centrales es la creencia según la cual 'el hombre es lo 
RIS

REISTA INTERNACIONAL DE SOCIOLOGIA

N" 20. Enero-dbril, 2001

ENRIQUE LARAÑA

que hace', ya que el triunfo de la Razón ha hecho posible una correspondencia cada vez más estrecha entre la producción, la tecnología y la organización de la sociedad según la ley, es decir, entre la acción humana y el orden del mundo (1993: 13). Actuando según la razón el hombre avanza al mismo tiempo hacia la abundancia, la felicidad y la libertad. Es una concepción endógena de la modernización que sitúa la fuente del cambio social en la estructura interna de la sociedad, en el proceso de racionalización que es su mecanismo espontáneo y esencial. De ese modo, la modernización prescinde de los sujetos, ya que no se considera "obra de un déspota ilustrado, de una revolución popular o de la voluntad de un grupo dirigente", sino de la razón misma, que se manifiesta a través de la ciencia, la tecnología y la educación (Touraine, 1993: 25).

Sin embargo, esa visión contrasta con la realidad: la gran mayoría de los países del mundo han seguido procesos de modernización muy diferentes, 'en los que la voluntad de independencia nacional, las luchas religiosas y sociales, las convicciones de nuevas élites dirigentes -es decir, los actores sociales, políticos y culturales- han tenido un papel más importante que la propia racionalización, paralizada por la resistencia de las tradiciones o los intereses privados' (op. cit: 25). En ello se basa el diagnóstico según el cual esa concepción de la Historia, como el alba de la razón que elimina toda separación entre el hombre y su sociedad, ha fracasado. Al igual que hace Giddens (1994), Touraine destaca que los hechos impugnan la concepción sansimoniana de una sociedad regida por el pensamiento objetivo y los expertos en su aplicación - una visión tecnocrática que ha informado a la concepción moderna de la Historia. "Ante todo porque la idea de que una administración racional de las cosas sustituiría al gobierno de los hombres es dramáticamente falsa" (Touraine, 1993: 50), dado que la vida social ha estado poblada de conflictos en lugar de que se produjese su disolución. Por eso es posible definir a esta concepción del mundo moderno como una ideología en el sentido que Mannheim (1936) emplea el término: como un conjunto de ideas incongruentes con la realidad, cuya función consiste en legitimar el estado de cosas existente.

El discurso sociológico sobre la crisis de la modernidad se funda en el análisis de la quiebra de una determinada concepción de la racionalidad que ha prevalecido en la sociedad industrial. A pesar de que parte de una perspectiva más optimista y también más influenciada por la concepción organicista del progreso, Bell hace un análisis que coincide con el de Touraine en un aspecto importante. Por una parte, afirma que la 'racionalidad funcional' es el principio axial del cambio en el orden tecnoeconómico de la sociedad industrial, lo cual explica su continuo crecimiento económico, al centrarse en el objetivo de maximizar los resultados de la actividad productiva y reducir sus costes (Bell, 1976 y 1977). Sin embargo, Bell (1976) anticipó el análisis sobre la crisis de la modernidad al indicar que esa forma de racionalidad se sustentaba en una concepción clásica de la sociedad que ha dejado de ser válida para interpretar 
lo que acontece en las sociedades industriales de Occidente, en las que se está produciendo una creciente separación entre sus distintos ámbitos o esferas sociales $^{8}$."El desarrollo de toda sociedad industrial avanzada y la aparición de la sociedad industrial dependen de la extensión de una dimensión particular de la racionalidad. Pero es precisamente esa definición de la racionalidad la que está siendo puesta en cuestión hoy en día" en ciertos ámbitos de la sociedad (Bell, 1976: 392). Su argumento es que en esa clase de racionalidad se sustentaba una concepción de la sociedad que ha dejado de ser válida para entender lo que acontece en las sociedades complejas, en las que se está produciendo una creciente diferenciación de tres subsistemas sociales (la estructura social, la política y la cultura). Estos ámbitos sociales se rigen por principios organizadores distintos y a veces contradictorios entre sí, ya que persiguen distintos fines y en cada uno de ellos se registran ritmos de cambio diferentes.

El aumento de la complejidad social cuestiona el supuesto central de la teoría sobre la modernidad, es decir, la correspondencia entre la producción y la organización de la sociedad en sus distintos ámbitos. Las "contradicciones culturales" de las sociedades complejas son fruto de las tensiones entre los principios por los que se rigen el orden tecnoeconómico, la cultura y la política (Bell, 1977). El principio axial en la estructura social es el de la "racionalidad funcional"; en la cultura, la búsqueda de identidad y la autorrealización personal; en el orden político los principios axiales son la igualdad de los ciudadanos ante la ley y la igualdad de oportunidades y derechos (Bell, 1980), así como los principios de legitimidad y participación? ${ }^{9}$. Un elemento básico en los procesos de diversificación cultural proviene del sincretismo que caracteriza a este ámbito de la sociedad postindustrial como consecuencia del incremento de la interacción, y del "derrumbamiento de las sociedades fragmentadas" o de las "culturas parroquiales'. El sincretismo es definido como "la mezcla de dioses extraños, como en la época de Constantino, o de artificios culturales en el arte moderno (hasta en los salones de las familias de profesionales de clase media). El sincretismo es la mezcolanza de estilos en el arte moderno que absorbe máscaras africanas o grabados japoneses... o la fusión de religiones orientales y occidentales, separadas de sus historias, en la conciencia moderna" (Bell, 1997: 26).

\footnotetext{
${ }^{8}$ Esa capacidad de anticipación parece provenir de la influencia que tiene la obra de Weber en la de Bell, como se indica más adelante.

${ }^{9}$ Esos tres ejes del orden político están relacionados en la medida en que la legitimidad de las decisiones sobre asuntos de interés general depende de la posibilidad de participación en ellas de las personas a las que afectan, lo cual remite a las formas en que se produce esta última. Desde la instauración del nuevo orden político propio de la sociedades modernas, la igualdad es la "condición implícita" para la legitimidad de esas formas de participación.
} 
RIS

REIISTA INTERNACIONAL DE SOCIOLOCIA

No 28. Enero-Abril. 2001

ENRIQUE LARAÑ

\section{LAS BASES DE UN NUEVO MARCO CONCEPTUAL}

El modelo de Bell sobre la sociedad postindustrial se funda en el surgimiento de un nuevo principio axial: la centralidad del conocimiento teórico para impulsar el crecimiento económico y la innovación tecnológica, y para hacer posible la planificación del cambio social. Bell intenta no caer en el error de otros sociólogos que le han precedido en la teorización del cambio social, y evitar la generalización de su pronóstico de cambios en ese orden a los otros dos ámbitos de la sociedad. De ahí su énfasis en la necesidad de distinguir entre ellos y evitar un modelo explicativo del cambio social extensible a todos los ámbitos de la sociedad.

La teoría de la sociedad postindustrial (Bell, 1976) fue presentada como un ensayo sobre el futuro, basado en una concepción diferente a la visión moderna y monolítica que había prevalecido en la sociología, es decir, como un esfuerzo por especificar los cambios que se estaban produciendo en uno de los ámbitos de la sociedad industrial (la estructura social), sin pretender extrapolarlos a los otros (Bell, 1976, 1977). La misma aproximación y una declaración de principios similar informan una difundida teoría reciente sobre el mismo tema. Castells afirma que el concepto informacionalismo designa el proceso de transformación de la estructura social como consecuencia del surgimiento de un nuevo modo de desarrollo basado en las tecnologías de la información e históricamente definido "por la reestructuración del modo capitalista de producción hacia finales del siglo XX" (1997: 40). Sin embargo, desde el comienzo del primer volumen de La era de la información, destaca que este proceso se manifiesta de distintas formas "según la diversidad de culturas e instituciones de todo el planeta" (Castells, 1997:40). El principio metodológico de la diferenciación de ámbitos se aplica en esta obra - al margen de que emplea términos distintos, pero equivalentes-, al afirmar que las sociedades están organizadas en torno a procesos humanos estructurados "por relaciones de producción, experiencia y poder, determinadas históricamente".

Junto con la intuición de Bell para discernir aspectos sustantivos de la transformación de las sociedades industriales avanzadas, probablemente ese principio epistemológico "de precaución", que implica un esfuerzo de autocontrol en un análisis tan ambicioso, sea una de las razones de la influencia de su obra. Sin embargo, la identificación de los principios axiales por los que se rige cada ámbito va cambiando en la obra de Bell, a veces con argumentos contradictorios. Por ejemplo, la imbricación entre los principios que estructuran el orden político se manifiesta en que cada uno desarrolla un aspecto del otro y conduce a pensar que en lugar de un sólo principio axial en el orden político puede haber varios relacionados entre sí. Este policentrismo del orden político en las sociedades avanzadas contrasta con su teoría, según la cual cada ámbito de la sociedad postindustrial se estructura en torno a un principio axial que actúa como centro 
simbólico de los procesos sociales. Para que ese modelo sobre el cambio social fuese realmente útil, sería necesario desarrollar estos conceptos y definirlos mejor. Si el análisis de los cambios en la estructura social es uno de los aspectos más influyentes de la obra de Bell (Lyon, 1988; Turner, 1990; Castells, 1997), el principio axial en esa esfera se sitúa alternativamente en la "racionalidad funcional" y en el papel del conocimiento teórico en la organización e innovación social. Este último es considerado como el principio-eje del cambio en el conjunto de la sociedad, lo cual contrasta con su teoría de la separación de ámbitos y con el objetivo de limitar su modelo a los cambios en la estructura social.

Si el principio axial de la sociedad postindustrial radica en la centralidad del conocimiento teórico - y éste solo es aplicable al orden tecnoeconómico donde rige otro principio - este concepto ("sociedad postindustrial") parece dar por hecho la existencia de un centro simbólico de la sociedad que está situado en la estructura social. En ese caso, la teoría de Bell se atiene a la lógica explicativa de los modelos clásicos e incurre en la línea de causalidad (la estructura social como ámbito determinante de lo que acontece en el resto de la sociedad) que el autor intenta evitar. En ese caso, su modelo reflejaría la tendencia a reducir la complejidad de estos procesos, que él mismo identifica como un problema central de las aproximaciones clásicas. Dicha tendencia sería fruto de la persistente influencia de la concepción monolítica de la sociedad, de la concepción moderna del cambio social y de los grandes teóricos de la sociedad industrial, al igual que ocurre con la fascinación por el desarrollo tecnológico y su impacto en nuestras sociedades ${ }^{10}$. Esa fascinación por el desarrollo tecnológico está presente tanto en Bell como en Castells y en la mayoría de los sociólogos que han tratado este tema. Por ello, esa visión prevaleciente ha sido designada como 'tecnófila' por Postman (1994). Sin embargo, el intento de poner límites a su modelo, y las críticas que éste recibió, condujo a Bell unos años después (1980) a renunciar al concepto "sociedad postindustrial" — que lleva implícita la "idea de totalidad" antes citada - y a proponer otro más acertado y menos ambicioso, postindustrialismo.

La influencia de la obra de Bell se manifiesta en obras tan dispares como el best-seller de Alvin Toffler sobre La tercera ola, las teorías de economistas como Naisbit (1983) y Masuda (1984) sobre la sociedad de la información, o la más reciente y relevante obra de Castells (1997), el cual utiliza muchas ideas de Bell, con quien reconoce una deuda intelectual. En síntesis, entre las razones por las que la obra de Bell ha tenido tal influencia habría que destacar, en primer

\footnotetext{
${ }^{10}$ Lo segundo está relacionado con lo primero y tiene su principal expresión en la premisa de la que parten la mayoria de estos trabajos clásicos, según la cual los cambios en el orden tecnoeconómico de la sociedad industrial explican el surgimiento de un nuevo tipo de sociedad.
} 
RIS

RETISTA INTERNACIONAL DE SOCIOLOCIA

N" 28. Enero-Abril. 2001

ENRIQUE LAR:NNA

lugar, su esfuerzo por conjurar la tentación a profetizar sobre el cambio en la sociedad, por limitar su pronóstico a lo que sucede en el orden tecnoeconómico de las sociedades industriales avanzadas y plantearlo como un conjunto de probabilidades sobre las cuales no hay ninguna certeza. En segundo lugar, su influencia se debe a la utilidad de ese pronóstico del cambio en ese ámbito, a su capacidad para identificar unas tendencias de organización y cambio social, que conducen al analista hacia el objeto adecuado de observación. Finalmente, pero no en último lugar, la influencia de la obra de Bell es debida a que su teoría de la separación de ámbitos cuestiona la concepción monolítica de la sociedad y la existencia de un centro simbólico que permite explicar lo que acontece en ella, y combina el análisis de series estadísticas sobre ocupación y organizaciones laborales con un buen conocimiento de los textos clásicos y contemporáneos sobre la sociedad industrial.

Sin embargo, mi argumento consiste en señalar que ni Bell ni Castells, como autores de teorías influyentes sobre la sociedad contemporánea, observan ese principio metodológico ni separan realmente los tres ámbitos de la sociedad. Sus teorías sobre el postindustrialismo y el informacionalismo siguen centradas en el orden tecnoeconómico como el ámbito explicativo de la transformación de la sociedad, que determina lo que sucede en los demás. De ese modo, ambos reproducen la concepción moderna de la sociedad de la que explícitamente se distancian. Y lo mismo sucede con los trabajos de Beck (1992, 1993, 1994, 1997) y Giddens $(1992,1994,1997)$ sobre la modernización reflexiva como he expuesto en otro lugar (Laraña, 1999b).

La cuestión entonces consiste en saber qué utilidad tienen estos modelos, lo cual remite a otra previa: en qué medida señalan el camino de la investigación y conducen al analista de la modernización hacia el objeto adecuado de observación ${ }^{11}$. En el caso de Bell, la imprecisión conceptual de su teoría de la modernización no invalida un análisis que se presenta como un mero "ensayo sobre el futuro", donde hay buenas intuiciones sobre los procesos de cambio social. Su utilidad depende de que los conceptos que propone se empleen como 'términos sensibilizadores' que no tienen carácter científico y que es preciso contrastar con los acontecimientos que inciden en este pronóstico del cambio social. El valor de esos supuestos proviene tanto de la imaginación sociológica del autor, como de la de los grandes sociólogos clásicos, en los que se funda su teoría (1976). El legado de la sociología clásica se manifiesta en su ambivalencia: por una parte, confiere interés y consistencia a esta teoría, que mantiene una

"Esta idea fue planteada por Aaron Cicourel en la reunión científica que organicé en Madrid en abril de 1999 para presentar los primeros trabajos de una investigación sobre sociedad de riesgo y movilizaciones colectivas. 
línea de continuidad con las de la sociedad industrial; por otra parte, ese legado bloquea el intento de apartarse de la lógica de interpretación de las teorías clásicas centradas en el papel determinante de la estructura social. Algo diferente sucede con las teorías de Castells sobre el informacionalismo o de Beck sobre la sociedad de riesgo, debido a la importancia que confieren al objetivo de construir una nueva tipología de organización y cambio social. La tendencia a dejarse llevar por ese ambicioso objetivo parece conducirles a reproducir la vieja concepción monolítica de la sociedad, en lugar de al estudio de los procesos en los que se gestan los cambios sociales.

La quiebra de la concepción monolítica de la sociedad y la historia occidental que analizó Bell en los años setenta es un supuesto recurrente en la teoría sobre la postmodernidad, de la cual se le considera precursor (Turner, 1991; Touraine, 1993). Bell anticipó la crisis de la visión de la sociedad como una totalidad estructuralmente unificada por una concepción del mundo centrada en su continuo progreso. En contra de lo que afirma el teorema citado de Hegel, la realidad se enfrenta una vez más a las estructuras conceptuales desde las que se interpreta y las transforma. Mi argumento es que ese análisis de Bell tiene su base en el de Weber sobre la estratificación social y las consecuencias del proceso de modernización $(1944,1964)$. Las aproximaciones estructuralistas clásicas situaban el principio estructurante de la sociedad en el orden económico (marxismo) o en el orden social (funcionalismo) y en un factor determinante (las clases o el prestigio, respectivamente). Weber impugnó esa concepción de la causalidad social al enfatizar la naturaleza pluridimensional del sistema de estratificación y la importancia del orden político en las oportunidades de vida de las personas $(1944,1964,1972)$.

Weber fue el primero en romper con la concepción monolítica de la sociedad como una estructura entrelazada y unificada por un principio central en el que se situaba la causalidad social. Y lo hizo a través del análisis de lo que acontece en uno de los campos centrales en la explicación sociológica, a saber: el de la forma en que surgen grupos sociales que comparten oportunidades de vida similares. En la capacidad del genial sociólogo alemán para establecer relaciones entre los dos niveles básicos del análisis sociológico - constituidos por la estructura social desigual y los grupos que comparten dichas oportunidades- radica su interés, y también su primacía sobre otros economistas y sociólogos. Esa lógica analítica le permitió relativizar el peso de la estructura social y sentar las bases de una sociología que se ocupa de la forma en que las relaciones de los individuos adquieren un papel central para definir sus oportunidades de vida. En el plano macrosociológico, la tipología de los tres factores (económicos, sociales y políticos) que dan lugar a distintas oportunidades de vida y a diferentes formas de agrupación social (clases, grupos de estatus y partidos) cuestionó la tendencia que había prevalecido en su tiempo a reducir las causas a un sólo ámbito o factor (tecnoeconómico) y anticipó la teoría de Bell al respecto. Al cuestionar la 
R I S

REUISTA INTERNACIONAL DE SOCIOLOGIA

Na 28. Enero-Abril, 2001

ENRIOUE LARANA

existencia de una esfera institucional que ocupa un lugar central en la sociedad moderna, Weber fue precursor de los enfoques constructivistas contemporáneos, y de una variedad de orientaciones a las que se suele designar como 'teorías sobre la postmodernidad'. Esto explica la persistencia de la obra de Weber en la actualidad y su condición de autor clásico en el sentido más amplio del término (Lamo de Espinosa, 1996; Laraña 1999)12. Y como todo clásico, en su obra hay supuestos que necesitan ser revisados y actualizados, uno de los cuales está íntimamente relacionado con el objeto de este trabajo, con cuya exposición concluyo.

\section{PARTICIPACIÓN SOCIAL Y FRONTERAS ENTRE ECONOMÍA Y POLÍTICA}

Frente a la tendencia corriente en la sociología a situar el principio de causalidad social en el orden tecnoeconómico, Weber destacó la diferencia que existe entre los intereses económicos y políticos, en torno a los cuales giran las actividades de las clases sociales y los partidos políticos. Con ello, cuestionó una identidad que parece haber obstaculizado el análisis sociológico de las relaciones entre esos dos grupos sociales, y mostró el papel de la cultura en la explicación del cambio más importante que se ha producido en ese orden económico. En este sentido, afirmó que el concepto de "interés" no sólo es una "categoría económica, sino un asunto político que responde a razones ideológicas o a un interés en el poder como tal" (Weber, 1964: 408). Esta interpretación se articula en su teoría de la diferenciación de la esfera política, basada en la conexión entre el proceso de racionalización y la separación de poderes que rige la organización política de la sociedad (op. cit: 404). En esta teoría se pone de manifiesto la influencia de la aproximación funcionalista a la modernización social como progresiva diferenciación estructural (Solé, 1998; Bell, 1976). Esta forma de organización política se diferencia de la que tiene lugar en grupos sociales independientes y surge del "antiguo sistema de estados" existentes en Europa como consecuencia del aumento de sus necesidades financieras en los primeros estadios de desarrollo del capitalismo (1964). Esta teoría no impide a Weber destacar la analogía existente entre la estructura de los partidos políticos y las

\footnotetext{
12 "Una obra 'clásica no es la que ha perdido vigencia y validez, sino aquélla que conserva estos atributos porque algunos de sus supuestos siguen siendo aplicables a la realidad social e iluminan el camino para su investigación. Por regla general, la utilidad de esas teorías clásicas es consecuencia de su síntesis con supuestos procedentes de otras recientes, de su fusión con lo "moderno" y del legado que éste recibe de lo "clásico" (Laraña, 1999).
} 


\begin{tabular}{rr} 
R I S \\
GLOBALLZACIÓN. CENTRO Y FrONTERAS SIMBÓLICAS... \\
\hline
\end{tabular}

empresas capitalistas basadas en la explotación del trabajo formalmente libre. El juego de intereses que orienta la acción social en la política y la economía es el mismo, lo que cambia es la naturaleza de éstos. En ello radica la semejanza entre las estructuras organizativas de empresas privadas y partidos políticos. En ambos casos, hay un grupo dirigente separado del resto y otro de miembros cuyo papel es mucho más pasivo. La diferenciación de roles en que se funda esta interpretación llega al máximo en los partidos políticos, caracterizados por la existencia de "una gran masa de miembros" de la sociedad global cuya función se limita a ser destinatarios de las propuestas de los partidos. "Dado el carácter voluntario de la participación, dicha estructura es inevitable" y determina las funciones de cada grupo (Weber, 1964: 411); la de los "miembros activos" del partido "simplemente consiste en aclamar a los líderes, si bien en ciertas circunstancias pueden ejercer alguna forma de control sobre ellos". Y para dirigentes y miembros, los demás ciudadanos "sólo tienen la consideración de objetos cuyo apoyo se busca en período electoral" (op. cit: 408).

La importancia de esta aproximación radica en su objeto, a saber: las formas de participación social a las que en este trabajo se atribuye una importancia central, y en el crudo escepticismo de Weber sobre su naturaleza. Ello es congruente con la influencia de la concepción sansimoniana de la sociedad industrial - que informa su teoría de la burocracia como una jaula de hierroy con la influencia de su obra en la de Michels sobre este tema. La idea de que dicha estructura de participación, desprovista de contenido real, es inevitable no sólo se funda en la creencia de que el destino de la sociedad moderna está en manos de las burocracias, sino que ese supuesto también muestra la influencia de la concepción moderna del cambio en la sociedad: sus causas inmanentes se sitúan en las nuevas élites que están en posesión del conocimiento técnico y encarnan un nuevo sistema de dominación del que nadie puede escapar. Esa teoría es aplicada por Weber al análisis de las formas de poder que se difunden en las empresas modernas, en virtud de la racionalización que produce ese modelo organizativo, lo cual se manifiesta en su capacidad para maximizar resultados. Y la analogía entre empresas y partidos amplía este análisis ${ }^{13}$.

Para Weber, la forma de organización en la que se funda esta dinámica es una exigencia del proceso de modernización social, cuya esencia es que el orden político constituya un espacio diferenciado. Ello exige que los partidos asuman el protagonismo de la participación social y la movilización colectiva, puesto que las otras formas de articular las demandas sociales (grupos de interés, opinión

\footnotetext{
${ }^{13}$ El carácter voluntario de los partidos los asemeja a las primeras y hace depender la continuidad en el poder de los dirigentes de los resultados electorales que cosechan, al igual que sucede con los directivos de las empresas modernas.
} 
RIS

REIISTA INTERNACIONAL DE SOCIOLOGIA

N" 28, Enero-.turil. 2001

ENRIOUE LARANA

pública y movimientos sociales) deben de integrarse en ellos. Los partidos son un instrumento básico del proceso (inmanente) de modernización política, ya que permiten canalizar esas demandas dentro de unas estructuras organizativas, lo cual hace posible traducirlas a términos más racionales. De este modo, los partidos políticos cumplen una función esencial para la existencia del orden social: posibilitar la inclusión de intereses contrapuestos, su combinación con los objetivos políticos del partido y los medios disponibles para su logro (Eisenstadt, 1972; Pérez-Agote, 1987).

En supuestos análogos se funda otra obra clásica que constituye la más dura y persistente crítica de los partidos políticos de masas. Formulada por su discípulo y amigo Robert Michels en 1917 (1984), analiza con detalle los mecanismos por los cuales los partidos tienden hacia un proceso de oligarquización inevitable (la concentración del poder en una cúpula dirigente separada del resto del partido, que actúa con el único propósito de preservar su continuidad en el poder). De ese modo, Michels amplió el análisis de Weber sobre el cierre de los sistemas de participación social y llevó al extremo las consecuencias de su teoría sobre la diferenciación de los partidos políticos, como instituciones centrales para articular la participación en la sociedad moderna. Si para Weber, la forma de organización en la que se funda esa situación viene impuesta por el proceso de modernización social, para Michels la ley de hierro de la oligarquía es consecuencia de un diagnóstico aún más negativo, basado tanto en esos supuestos, como en su experiencia personal en partidos socialdemócratas en Alemania e Italia: la raíz de esa ley radica en la incompatibilidad entre democracia y organización.

Este modelo de participación social viene siendo cuestionado desde los años sesenta por una variedad de personas y grupos que dan lugar a los movimientos sociales característicos de las sociedades complejas. Un factor central en su génesis son las consecuencias perversas del proceso de modernización política, analizado por Weber y Michels, las cuales se manifiestan entre los ciudadanos como sentimientos de desconfianza hacia los cauces existentes para la participación en asuntos públicos en las democracias occidentales (Flacks, 1989; Johnston, Laraña y Gusfield, 1994). Ese fenómeno afecta especialmente a las asociaciones políticas y da lugar a la tendencia de los movimientos sociales a mantener un alto grado de independencia de los partidos. En algunas organizaciones de movimientos sociales, esa identidad pública independiente ha influido directamente en sus posibilidades de alinear a potenciales seguidores con sus marcos de acción colectiva ${ }^{14}$.

\footnotetext{
${ }^{14}$ Es el caso de las movilizaciones estudiantiles que he estudiado en España en 1987 y 1993 (Laraña 1999).
} 
Las relaciones de autonomía entre movimientos y partidos nos permiten identificar tres grandes periodos en la evolución histórica de los movimientos sociales en España (Laraña, 1999). La importancia que adquiere ese principio organizativo en el periodo actual, que comienza a mediados de los años ochenta, marca diferencias básicas con lo que sucedía en el periodo moderno, vigente en época de Franco y la primera transición, y ello está directamente relacionado con el fuerte aumento de la participación en asociaciones voluntarias durante la última década.

En los movimientos sociales que surgen en las sociedades complejas, la tendencia hacia la autonomía respecto de los partidos se pone de relieve tanto en las definiciones de la situación que promueven sus organizaciones, como en los marcos de significados de sus seguidores, y suele ir unida a la búsqueda de formas alternativas de participación, más directas y próximas a los colectivos implicados (Hirsch, 1990; Flacks y Whalen, 1989). El rechazo a integrarse en la estructura burocrática de los partidos que caracteriza a los seguidores de estos movimientos no sólo es consecuencia de la pérdida de credibilidad de los primeros, sino que es progresivamente considerado por sus seguidores como condición para la participación en ellos.

El significado de estos movimientos está claramente relacionado con el objeto de este trabajo, ya que ponen de manifiesto el resquebrajamiento de las fronteras que han separado la esfera política de la vida cotidiana en el anterior estadio de modernización y las tendencias centrífugas que se están produciendo en el orden político. El fenómeno consiste en una pérdida de confianza en los instrumentos de conexión entre los ciudadanos y el centro simbólico de la sociedad. Ese centro es el Estado, cuya conquista se ha convertido en la razón de existencia de los partidos, como elementos de estructuración de la vida pública en torno a esa institución central. Esa dinámica de lucha por el poder parece intimamente relacionada con la ley de hierro que formula Michels y está en la raíz de la pérdida de confianza en los partidos. El significado de este proceso no se limita a una simple pérdida de confianza en estas organizaciones, ya que afecta al modelo de organización política en las democracias occidentales, es decir, a los cimientos del orden social. En términos de Weber (1964), la transcendencia de esa crisis proviene de su capacidad de socavar las bases de autoridad política en las cuales radica la legitimidad de las decisiones más importantes en las sociedades modernas y, en general, las formas de 'coordinación imperativa' que son imprescindibles para el funcionamiento de una sociedad al permitir racionalizar las relaciones de dominación, lo cual es la esencia de la modernización política. En relación con lo segundo, un proceso paralelo está teniendo lugar en el ámbito de la autoridad científica, protagonizado por los movimientos ecologistas que muestran el papel de los movimientos contemporáneos en la quiebra de la visión sansimoniana de la sociedad. Junto con la marxista, esta profecía de una sociedad gobernada por los técnicos y estructurada sobre la base 
del conocimiento objetivo, fue la expresión más radical de las que formularon los clásicos sobre la sociedad moderna y el progreso occidental.

Las tendencias centrífugas que están transformando el escenario político en las sociedades occidentales explican parte del actual interés por los movimientos sociales contemporáneos que, de ser considerados fenómenos marginales en una influyente teoría funcionalista, han pasado a ocupar un lugar central en los procesos de cambio social (McAdam, 1982 y 1994; Melucci, 1989 y 1996). Ello está relacionado con otro aspecto central sobre el significado simbólico de estos movimientos, los cuales buscan y llevan a la práctica formas de participación social en las que los asuntos privados se funden con los públicos, y las cuestiones vinculadas al desarrollo de la identidad personal a las relacionadas con la identidad colectiva de sus seguidores (Turner, 1969 y 1994; Johnston, Laraña y Gusfield, 1994; Melucci, 1994). Los movimientos sociales contemporáneos cuestionan el principio de diferenciación de la esfera política en que se ha fundado la organización social en Occidente, así como las consecuencias modernizadoras que se atribuyen a los partidos (privatizar la vida social y desmovilizar a los grupos sociales). Por ello, representan una respuesta a las formas de participación social que establece este modelo y una manifestación de la reflexividad de las sociedades complejas, al mostrar las consecuencias no queridas del modelo de modernización política occidental. De ahí su condición de 'mensajes simbólicos' y agencias de significación colectiva que difunden nuevas ideas sobre la naturaleza de la democracia, como proceso en desarrollo para la organización de la vida pública. En ello radica buena parte de su fuerza para democratizar las instituciones sociales (Melucci, 1989 y 1996; Snow y Benford, 1988; Cohen, 1985; Laraña, 1999).

\section{REFLEXIVIDAD Y CAMBIO SOCIAL}

Este artículo termina con una reflexión sobre el modelo prevaleciente sobre la modernización y los cambios que se están produciendo en las relaciones establecidas entre el orden tecnoeconómico y la política. Está basada en comentarios centrados en la reflexividad del cambio social, que se manifiesta en el análisis de las consecuencias no intencionadas de la modernización en las sociedades occidentales, desde los nuevos riesgos colectivos generados por el desarrollo científico-técnico, la crisis de las tradiciones culturales y las formas de estructuración social, hasta los que tienen lugar en las relaciones entre los sexos ${ }^{15}$ (Beck, 1992, 1993, 1995, 1997; Giddens, 1990, 1994, 1997). Para Giddens, el significado de estos hechos consiste en cuestionar la concepción occidental de la modernidad, un fenómeno que no sólo afecta a los países donde se difundió, sino al mundo en su conjunto, que ha sido configurado por ella. Sin embargo, la crisis de esa visión se manifiesta en la reflexividad de la historia social: el 
efecto de esos procesos de cambio social consiste en dar una nueva forma a la modernidad y 'retrotraerla a sus inicios', radicalizar y recuperar los supuestos de la Ilustración que se han perdido (Giddens, 1994: 80) ${ }^{16}$.

Esta interpretación está siendo objeto de críticas en las que se destacan las discontinuidades entre ambos tipos de sociedad y cuestionan esa coŕcepción (Lash et al., 1996; Feathersome y Lash, 1995; Robertson, 1995). Esas críticas son ampliadas por el análisis de la utilidad que tiene esa teoría de la moderniazación reflexiva para el estudio de los procesos generadores de reflexividad en otro sentido, en el plano intermedio de los grupos que los protagonizan y en el contenido simbólico de los primeros. El supuesto sobre la continuidad entre sociedades industriales y de modernización reflexiva, que informa a las teorías de Bell y Giddens, parece fundado en la misma concepción organicista del cambio social que ha prevalecido en nuestra cultura e informa las concepciones monolíticas de la sociedad.

Sin embargo, en estas teorías hay ideas de interés para construir una nueva aproximación a las sociedades contemporáneas y su proceso de transformación. Para Beck (1992), el modelo de organización política en las democracias occidentales se funda en los límites que existían entre los derechos y deberes del ciudadano como tal y como persona interesada en la defensa de sus derechos de propiedad: los primeros se plantean en el campo de la política y los segundos en el de la no-política. Este "modelo dividido del ciudadano" establece su derecho a participar en las decisiones que se toman en la primera y abstenerse de hacerlo en el ámbito de la segunda, y se basa en la separación entre el sistema político y el tecnoeconómico. Beck retoma el argumento con el que Mills (1964) formuló su crítica de las grandes corporaciones de negocios y lo desarrolla en otra dirección. El sistema tecnoeconómico permanece fuera del control político porque es el ámbito donde se gestan procesos de cambio social y técnico que

\footnotetext{
${ }^{15}$ En ello se funda una tipología de las sociedades; ésta es definida en términos de 'modernización reflexiva' y es la que existe en las sociedades complejas frente a las formas de 'modernización simple' propias de las sociedades industriales. En contraste con los procesos de modernización simple, nuestras sociedades occidentales se caracterizan por la complejidad, la incertidumbre y unos peligros colectivos que amenazan a todas las formas de vida.

${ }^{16}$ Un mundo de 'reflexividad social intensificada' se caracteriza por la existencia de individuos reflexivos que responden a las incertidumbres y 'pueden subvertir los incentivos económicos por los que antes se suponía que se movilizaban'(Giddens 1994: 42). En contraste, las sociedades de modernización simple estaban integradas por una ciudadanía con estilos de vida estables y donde los factores tradicionales de estructuración (la familia, la clase, el barrio) eran la base de sentimientos de seguridad y certeza que hoy están cambiando. Para Giddens, la postmodernidad no es más que la radicalización de las características propias de la sociedad moderna.
} 
R I S

RETISTA INTERNACIONAL DE SOCIOLOGIA

N" 28. Enero-Abril. 2001

ENRIOUE LARANA

están legitimados por la ideología modernista del progreso; ello hace que esos cambios se consideren resultado de constricciones objetivas, de una especie de "ley de vida" de la modernización

Sin embargo, la responsabilidad de ese sector tecnoeconómico en la producción de los nuevos peligros colectivos que amenazan a todas las formas de vida, está rompiendo esas demarcaciones y cuestiona el modelo de organización política en que se fundaban (Beck, 1992 y 1995). La pérdida de confianza en los cauces políticos tradicionales sería consecuencia de la incapacidad de éstos para promover políticas efectivas frente a esas amenazas. La decepción de los ciudadanos con la política proviene según Beck de la tensión entre una progresiva conciencia de riesgo y el modelo de organización política occidental. Esa separación formal provoca el "desencadenamiento de la política" (unbiding of politics), que en realidad es el de aquello tradicionalmente considerado como "no-política": la proliferación de demandas y movilizaciones que se plantean fuera de la primera y el surgimiento de una "nueva cultura política" que confiere sentido a la participación en las segundas.

A este proceso subyace la ruptura del modelo de modernización de la sociedad basado en la separación de estos ámbitos. En el político, su progresiva debilidad no puede ser considerada como un fracaso, sino como el producto de una democracia establecida y del Estado del Bienestar, que permiten a los ciudadanos usar todos los medios públicos y legales de control y asesoramiento para proteger sus propios intereses y derechos. Por otra parte, el orden tecnoeconómico pierde su carácter apolítico "conforme aumenta su potencial de generar cambio social y de poner en peligro a la sociedad" (Beck, 1992: 185). "Las condiciones en que se articulaba la separación entre política y no-política pierden consistencia en el curso de la modernización reflexiva como consecuencia de la importancia social que adquieren los riesgos" y "aquello que hasta ahora era considerado apolítico se convierte en político" (op cit: 190,24). En el fondo de esta difuminación de los límites que demarcaban distintos ámbitos de la sociedad, late el proceso de globalización de nuestro tiempo. Los riesgos son vividos por todos, se distribuyen más allá de las posiciones de clase, las relaciones Norte-Sur y la separación entre política y no-política.

\section{BIBLIOGRAFÍA}

ARON, R. (1971), Dieciocho lecciones sobre sociedad industrial, Seix Barral, Barcelona.

BALANDIER, G. (1971), Sens et puissance, París, PUF. 
BECK, U. (1992), Risk Society. Towards a New Modernity, Sage, Londres.

(1993), "De la sociedad industrial a la sociedad del riesgo. Cuestiones de supervivencia", Revista de Occidente, $\mathrm{n}^{\circ}$ 150, Madrid.

(1995), Ecological Politics in a Age of Risk, Policy Press, Cambridge.

(1997), "La reinvención de la politica: hacia una teoría de la modernización reflexiva", en U. Beck, Modernización reflexiva. Política, tradición y estética en el orden social moderno, A. Giddens y S. Lash (eds.) Alianza, Madrid.

BELL, D. (1976), La llegada de la sociedad postindustrial, Alianza Editorial, Madrid.

(1977), Las contradicciones culturales del capitalismo, Alianza Editorial, Madrid.

(1980), The Winding Passage: Essays on Sociological Journeys, 1960-1980, ABT Books, Cambridge.

COHEN, J. (1985), "Strategy or Identity: New Theoretical Paradigms and Contemporary Social Movements", Social Research, vol. 52, nº 4.

COMTE, A. (1980), Discurso sobre el espíritu positivo, Aguilar, Buenos Aires.

DAVIS, K. y W. MOORE”(1972), "Algunos principios de estratificación”, en R. Bendix y S. Lipset (eds.) Clase, status y poder, Euramérica, Madrid, vol. I.

DIANI, M. (1992), “The concept of social movement”, The Sociological Review, nº 40.

DURKHEIM, E. (1985), La división del trabajo social, Planeta, Barcelona.

FEATHERSOME, K. y S. LASH (1995), "Globalization, Modernity and Spatialization of Social Theory: an Introduction”, en M. Featherstone, S. Lash y R. Robertson (eds), Global Modernities, Londres, Sage.

FLACKS, R. (1994), "El partido ha terminado ¿Qué hacer con la crisis de los partidos políticos?", en E. Laraña y Gusfield (eds.), Los nuevos movimientos sociales. De la ideología a la identidad, Centro de Investigaciones Sociológicas, Madrid.

FLACKS, R. y J. WHALEN (1989), Beyond the Barricades. The Sixties Generation Grows Up, Temple University Press, Philadelphia.

GIDDENS, A. (1990), The Consequences of Modernity, Polity Press, Londres (Versión española en Alianza Universidad, Madrid, 1994).

(1994), Beyond Left and Right. The Future of Radical Politics, Polity Press, Cambridge.

(1997), "Vivir" en una sociedad postradicional", en U. Beck, A. Giddens y S. Lash, Modernización reflexiva. Política, tradición y estética en el orden social moderno (eds.) Alianza Editorial, Madrit. 
GOFFMAN, E. (1959), The Presentation of Self in Everyday Life, Anchor Books, New York.

[1974] (1986), Frame Analysis, Northeastern University Press, Boston.

GUSFIELD, J. (1994), "La reflexividad de los movimientos sociales: el valor de las teorias sobre la sociedad de masas y el comportamiento colectivo", en E. Laraña y J. Gusfield (eds.), Los nuevos movimientos sociales. De la ideologia a la identidad. Centro de Investigaciones Sociológicas, Madrid.

HIRSCH, E. (1990), "Sacrifice for the Cause: Group Processes, Recruitment, and Commitment in a Student Social Movement", American Sociological Review, vol 55 (april).

JOHNSTON, H., E. LARAÑA y J. GUSFIELD (1994), "Identidades, ideologías y vida cotidiana en los nuevos movimientos sociales", en E. Laraña y J. Gusfield (eds.), Los nuevos movimientos sociales. De la ideología a la identidad, Centro de Investigaciones Sociológicas, Madrid.

KORNHAUSER,W. (1969), Aspectos politicos de la sociedad de masas, Amorrortu, Buenos Aires.

LAMO de ESPINOSA, E. (1996), Sociedades de cultura, sociedades de ciencia, Madrid, Ediciones Nobel.

LARAÑA, E. (1984), "Cambio Social", en S. del Campo (coord.), Tratado de Sociologia, vol. II, Taurus, Madrid.

(1994), "Continuidad y unidad en las nuevas formas de acción colectiva. Un análisis comparado de los movimientos estudiantiles", en E. Laraña y J. Gusfield (eds.), "Los nuevos movimientos sociales. De la ideología a la identidad", Centro de Investigaciones Sociológicas, Madrid.

(1999), La construcción de los movimientos sociales, Alianza Editorial, Madrid.

(2001a), "Reflexivity, Risk and Collective Action Over Waste Management. A Contructive Proposal", Current Sociology, vol. 49, nº 1, pp. 23-48.

(2001b), "Teoría y método en la investigacion de la reflexividad y los riesgos tecnológicos", en La constitución social de la subjetividad, E. Crespo y C. Soldevilla (eds.), Madrid, Libros de la Catarata, pp. 227-244.

LASH, S. y J. ULRICH (1994), Economies of Signs and Space, Londres, Sage.

LASH, S., B. SZERSZYNSKI y B. WYNNE (1996), Risk, Environment and Modernity, Londres, Sage.

LYON, D. (1988), The Information Society. Issues and Illusions, Polity Press, Oxford.

LYOTARD, J. F. (1984), The Postmodern Condition, Manchester University Press, Manchester.

MANNHEIM, K. (1936), Ideology and Utopia, Harvest Books, New York. 
MASUDA, J. (1984), La sociedad postindustrial como sociedad de la información, Fundesco, Madrid.

McADAM, D. (1982), Political Process and the Development of Black Insurgency 1930-1979, University of Chicago Press, Chicago.

McCARTHY, J. y M. ZALD (1987), Social Movements in an Organizational Society, Transaction, New Brunswick.

MELUCCI, A. (1989), Nomads of the Present, Temple University Press, Philadelphia.

(1994), “Qué hay de nuevo en los nuevos movimientos sociales?”, en E. Laraña y Gusfield (eds.), Los nuevos movimientos sociales. De la ideología a la identidad, Centro de Investigaciones Sociológicas, Madrid.

(1996), Challenging Codes. Collective Action in the information age, Cambridge University Press, Cambridge.

MICHELS, R. (1984), Los paríidos políticos. Un estudio sociológico de las tendencias oligárquicas de la democracia moderna, Amorrortu, Buenos Aires.

MILLS, C.W. (1959), The Sociological Imagination, Grove Press, New York (Traducido al castellano en el Fondo de Cultura Económica).

NAISBIT, J. (1983), Macrotendencias, Mitre, Barcelona.

NEEDELMAN, B. y P. STOMPKA (1994), "Introduction", en Needelman y Stompka (eds.) Sociology in Europe. In Search for Identity, Berlin, Walter de Gruyter.

NISBET, R. (1979), "El problema del cambio social”, en R. Nisbet, T. S. Kuhn, L. Whyte (eds.), Cambio social, Alianza. Editorial, Madrid.

OLSON, M. (1963), The Logic of Collective Action, Harvard University Press, Cambridge.

PARSONS, T. y G. PLATT (1975), The American University, Cambridge MA, Harvard University Press 1973.

PÉREZ DÍAZ, V. (1987), El retorno de la sociedad civil, Instituto de Estudios Económicos, Madrid.

PÉREZ-AGOTE, A. (1987), El nacionalismo vasco a la salida del franquismo, Centro de Investigaciones Sociológicas, Madrid.

POSTMAN, N. (1994), Tecnópolis. La rendición de la cultura a la tecnología, Círculo de Lectores, Madrid.

ROBERTSON, R. (1995), "Glocalization: Time-Space and Homogeneity-Heterogeneity", en M. Featherstone, S. Lash y R. Robertson (eds.), Global Modernities, Londres, Sage. 
RIS

RETISTA INTERNACIONAL DE SOCIOLOGI.

N" 28. Enero-dbril. 2001

ENRIQUE LARAÑ.

SAINT-SIMON, H. (1975), El sistema industrial, Ediciones de la Revista de Trabajo, Madrid.

SOLÉ, C. (1998), Medio Ambiente: prevención y control de residuos sólidos urbanos, Bilbao, Fundación BBV.

TOURAINE, A. (1993), Critica a la modernidad, Madrid, Temas de Hoy.

TURNER, B. (1990), "Defining Posmodernity", en Bryan Turner (ed.), Theories of Modernity and Postmodernity, Londres, Sage.

WALLERSTEIN, I. (1992), "America and the world", Theory and Society, n² 21, pp. 1-28

(1994), "Letter from the president", nº 1, ISA, Bulletin 64.

WEBER, M. (1942), Historia económica general, Fondo de Cultura Económica, México,

(1944), Economía y sociedad, Fondo de Cultura Económica, México.

(1972), "Clase, Status y partido", en Bendix y Lipset, Clase, Status y poder, Euramérica, Madrid. 